\title{
An unusual cause of lower gastrointestinal haemorrhage
}

\author{
Azara Janmohamed, ${ }^{1}$ Lizanne Noronha, ${ }^{1}$ Ashish Saini, ${ }^{2}$ Colin Elton ${ }^{3}$ \\ ${ }^{1}$ General Surgery Department, Barnet Hospital, London, UK: \\ ${ }^{2}$ Radiologist Department, Barnet Hospital, London, UK: \\ ${ }^{3}$ Colorectal Surgery Department, Barnet Hospital, London, UK \\ Correspondence to Dr Azara Janmohamed, a.janmohamed@doctors.org.uk
}

\section{Summary}

A previously unreported cause of lower gastrointestinal haemorrhage in a 63-year-old female patient on clopidogrel for cardiac comorbidities is presented. Endoscopy suggested a small bowel or colonic aetiology but failed to accurately localise the source. The patient became haemodynamically unstable despite conservative management and temporary cessation of clopidogrel. CT angiography demonstrated a pseudoaneurysm arising from the superior rectal artery. Percutaneous embolisation using coils was performed to successfully occlude the pseudoaneurysm, prevent further haemorrhage and avoid emergency colonic resection.

\section{BACKGROUND}

Massive lower gastrointestinal (GI) haemorrhage is most commonly due to diverticulosis. Other causes include vascular anomalies, ischaemic colitis, inflammatory bowel disease, haemorrhoids and neoplasms.
Visceral artery aneurysms are rare (incidence $0.01-$ $0.2 \%) .{ }^{1}$ They are normally asymptomatic and found incidentally. Despite this they are treated due to the high risk of rupture. Inferior mesenteric artery aneurysms account for $1 \%$ of all visceral artery aneurysms. To our knowledge,

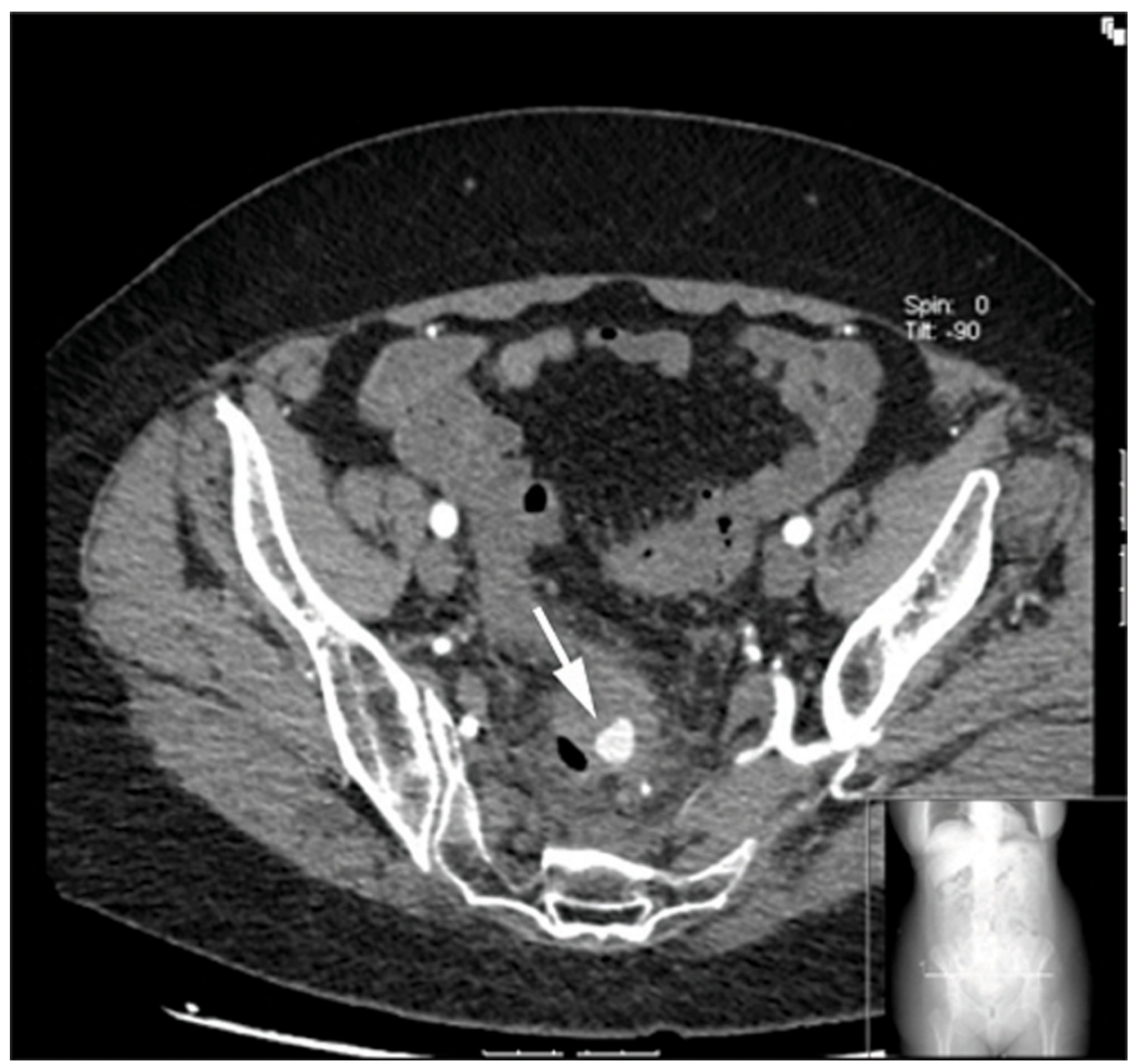

Figure 1 Axial contrast enhanced CT (arteriographic phase) demonstrating the pseudoaneurysm (arrow) as a bulbous vascular sac. The adjacent sigmoid mesentry is inflamed. 


\section{BMJ Case Reports}

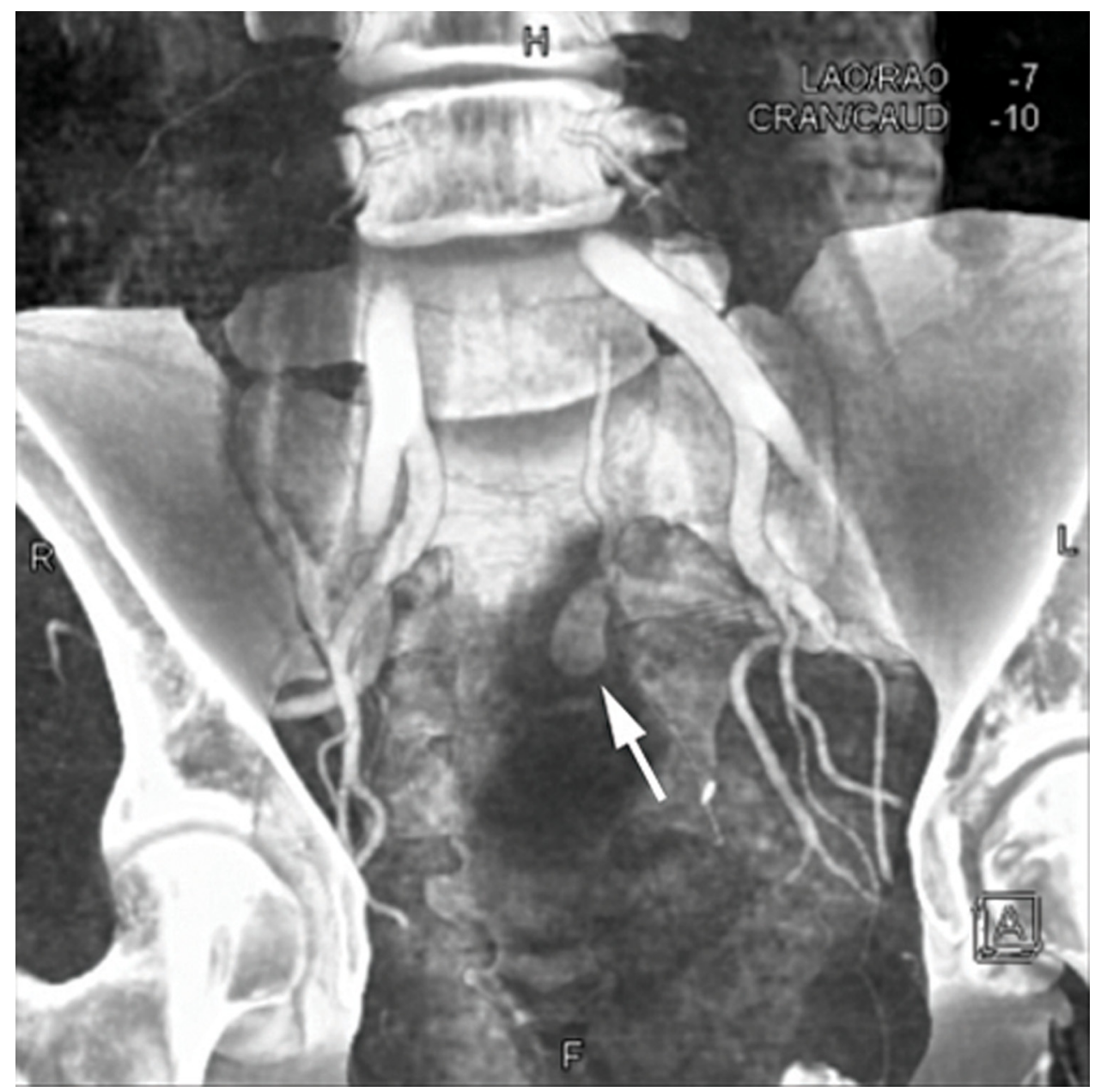

Figure 2 Volume rendered maximum intensity projection CT. The superior rectal artery can be seen as a vertically orientation vessel leading to the pseudoaneurysm (arrow).

this is the first reported case of a non-traumatic superior rectal artery pseudoaneurysm causing a lower GI bleed. The incidence of superior rectal artery aneurysms and pseudoaneurysms is unknown. Only one case has been reported, which highlighted a lower GI bleed caused by a traumatic pseudoaneurysm of the superior rectal artery secondary to previous surgery. ${ }^{2}$

This case report highlights the use of CT angiography as a modality to identify unusual causes of GI bleeding when endoscopy has not been fruitful. A systematic approach to GI investigations is important to identify both common and unusual causes. Visceral aneurysms and pseudoaneurysms can cause GI haemorrhage and extraluminal haemorrhage into the peritoneal cavity. Radiological embolisation is the treatment of choice although surgery can be employed if embolisation fails.

\section{CASE PRESENTATION}

A 63-year-old woman presented to the emergency department with a 5 day history of fresh per rectal bleeding. She had central, colicky abdominal pain and feeling light headed. She had no history of weight loss or change in bowel habit. Her comorbidities included cardiac syndrome X, previous TIAs and breast cancer (treated with wide local excision and radiotherapy). Her regular medications included clopidogrel, bisoprolol, isosorbide mononitrate, diltiazem and nicorandil. She was allergic to aspirin. On examination, she looked pale with a blood pressure (BP) of 102/66, pulse $65 \mathrm{bpm}$ (regular), oxygen saturations of $100 \%$ on air. Her abdomen was soft and tender below the umbilicus. There were no palpable masses and bowel sounds were present. Per rectal examination revealed no haemorrhoids or masses, but altered blood was observed. Antiplatelet agents were withheld, but she continued to bleed and became haemodynamically unstable (BP 98/55, HR 85). Haemoglobin on admission was 10.9 and this fell to 7.55 days later. ECG showed ischaemic changes. She was transfused with three units of packed red cells.

\section{INVESTIGATIONS}

Flexible sigmoidoscopy revealed florid localised sigmoid diverticuloses. Patchy associated erythema was also observed. She had sizeable haemorrhoids. There were no mass lesions.

Oesophageogastroduodenoscopy revealed mild antral gastritis, with normal mucosal appearances and no bleeding points.

As all the usual investigations for a lower GI bleed revealed no source, a CT angiogram was carried out. This demonstrated a pseudoaneurysm arising from the superior rectal artery (figures 1 and 2). 


\section{BMJ Case Reports}

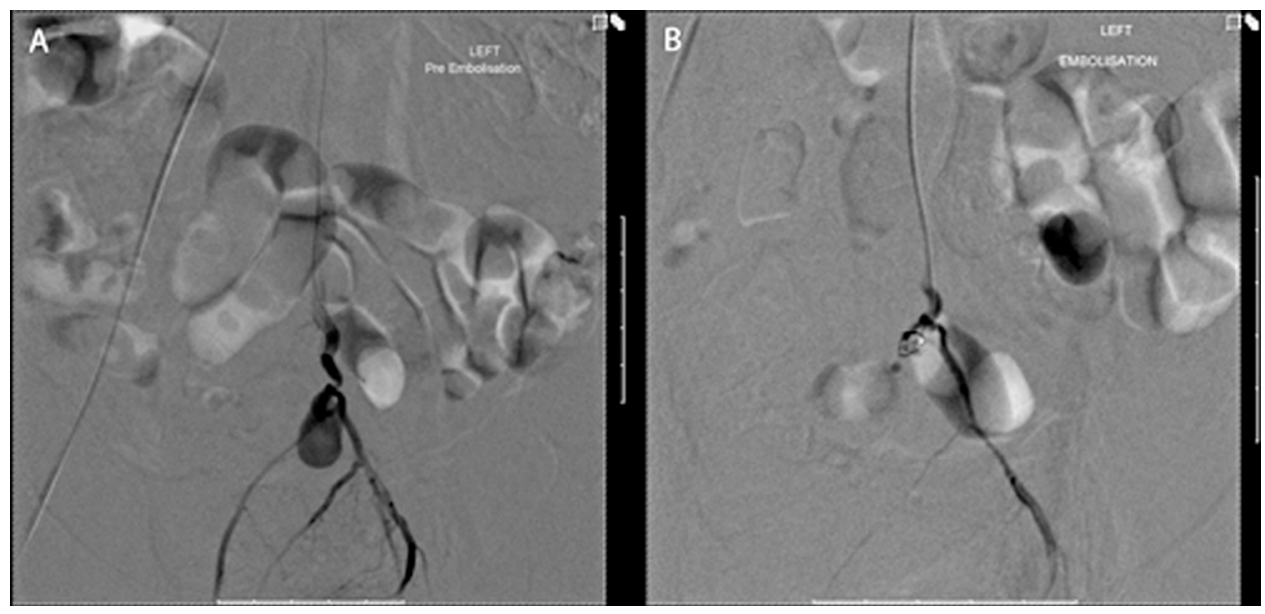

Figure 3 (A) Pre-embolisation selective inferior mesenteric arteriogram demonstrates the pseudoaneurysm arising from the proximal superior rectal artery. The distal branches supplying the rectum are clearly seen. (B) Post embolisation arteriogram. Coils have been placed at the origin of the pseudoaneurysm, causing thrombosis of the aneurysm sac. The distal superior rectal artery has been preserved.

\section{DIFFERENTIAL DIAGNOSIS}

Diverticular disease, vascular malformations (angiodysplasia), ischaemic colitis, haemorrrhoids, inflammatory bowel disease (eg, ulcerative proctitis, Crohn's disease), neoplasia (carcinoma or polyps) and radiation enteropathy.

\section{TREATMENT}

The pseudoaneurysm was occluded by percutaneous coil embolisation under fluoroscopic guidance (figure 3).

\section{OUTCOME AND FOLLOW-UP}

Postembolisation, the patient had deep pelvic pain thought to be due to temporary arterial spasm causing loss of antegrade flow in the distal superior rectal artery. This resolved over $24 \mathrm{~h}$ and the patient was monitored for sepsis secondary to rectal ischaemia. She was discharged 8 days post embolisation and during this period there were no further episodes of per rectal bleeding. Prior to discharge, she was restarted on clopidogrel.

\section{DISCUSSION}

Lower GI haemorrhage is a common (20-27 cases per 100000 in the Western world) and life-threatening condition with a mortality of $10-20 \% .^{3}$ There are many conditions that present with per rectal bleeding, the most common of which is diverticulosis. Accurately identifying the source of bleeding is critical to effective treatment. Systematic evaluation of the source of bleeding is important. The usual investigations include upper GI endoscopy and colonoscopy. Sometimes however, an endoscopy may be inconclusive. Increasing data highlights the importance of CT angiography as a rapid, non-invasive method of accurately localizing the site of bleeding. ${ }^{45}$ A recent metaanalysis assessing the accuracy of CT angiography in the diagnosis of acute GI bleeding showed a pooled sensitivity of $89 \%(95 \%$ CI 82 to $94 \%)$ and specificity of $85 \%(95 \%$ CI 74 to $92 \%){ }^{6}$

Visceral artery aneurysms are rare (incidence 0.01$0.2 \%) .{ }^{1}$ They are normally asymptomatic and found incidentally. Despite this they are treated due to the high risk of rupture. The most commonly affected vessels include splenic, hepatic, superior mesenteric and coeliac artery. ${ }^{7-9}$ Pseudoaneurysms arise from a disruption in arterial wall, with blood dissecting into the tissues around the damaged artery creating a perfused sac that communicates with the arterial lumen. They may be traumatic, iatrogenic (from surgical, endoscopic or radiological interventional procedures) or arise from inflammatory or infectious conditions. ${ }^{10-12}$ The cause of this patient's pseudoaneurysm is acute diverticulitis. Radiological embolisation is the treatment of choice although surgery can be employed when embolisation fails. The percutaneous approach offers a non-invasive solution in treating aneurysms that are difficult to manage surgically. ${ }^{13}$ This approach further allows surgical intervention should a percutaneous approach not be successful. ${ }^{11} 1415$

\section{Learning points}

- Systematic Gl investigations need to be carried out to pick up both common and unusual causes of per rectal bleeding.

- CT angiography is an important non-invasive, sensitive and widely available modality to identify the cause of Gl bleeding when endoscopy has failed.

- Radiological embolisation approach offers a minimally invasive solution in treating aneurysms that are difficult to operate surgically.

\section{Competing interests None}

Patient consent Obtained.

\section{REFERENCES}

1. Chadha $\mathbf{M}$, Ahuja C. Visceral artery aneurysms: diagnosis and percutaneous management. Semin Intervent Radiol 2009;26:196-206.

2. Iqbal J, Kaman L, Prakash M. Traumatic pseudoaneurysm of superior rectal artery - an unusual cause of massive lower gastrointestinal bleed: a case report. Gastroenterol Res 2011;4:36-8.

3. Manning-Dimmitt LL, Dimmitt SG, Wilson GR. Diagnosis of gastrointestinal bleeding in adults. Am Fam Physician 2005;71:1339-46.

4. Laing CJ, Tobias T, Rosenblum DI, et al. Acute gastrointestinal bleeding: emerging role of multidetector CT angiography and review of current imaging techniques. Radiographics 2007;27:1055-70. 


\section{BMJ Case Reports}

5. Stunell H, Buckley 0, Lyburn ID, et al. The role of computerized tomography in the evaluation of gastrointestinal bleeding following negative or failed endoscopy: a review of current status. J Postgrad Med 2008;54:126-34.

6. Wu LM, Xu JR, Yin Y, et al. Usefulness of CT angiography in diagnosing acute gastrointestinal bleeding: a meta-analysis. World J Gastroenterol 2010; 16:3957-63.

7. Chiesa R, Astore D, Guzzo G, et al. Visceral artery aneurysms. Ann Vasc Surg 2005; 19:42-8.

8. Huang YK, Hsieh HC, Tsai FC, et al. Visceral artery aneurysm: risk factor analysis and therapeutic opinion. Eur J Vasc Endovasc Surg 2007; 33:293-301.

9. Sachdev U, Baril DT, Ellozy SH, et al. Management of aneurysms involving branches of the celiac and superior mesenteric arteries: a comparison of surgical and endovascular therapy. J Vasc Surg 2006;44:718-24.
10. Carmeci C, McClenathan J. Visceral artery aneurysms as seen in a community hospital. Am J Surg 2000;179:486-9.

11. Parildar M, Oran I, Memis A. Embolization of visceral pseudoaneurysms with platinum coils and N-butyl cyanoacrylate. Abdom Imaging 2003;28:36-40.

12. Sessa C, Tinelli G, Porcu P, et al. Treatment of visceral artery aneurysms: description of a retrospective series of 42 aneurysms in 34 patients. Ann Vasc Surg 2004;18:695-703

13. Laganà $\mathbf{D}$, Carrafiello $\mathrm{G}$, Mangini $\mathrm{M}$, et al. Multimodal approach to endovascular treatment of visceral artery aneurysms and pseudoaneurysms. Eur J Radiol 2006;59:104-11.

14. Gabelmann A, Görich J, Merkle EM. Endovascular treatment of visceral artery aneurysms. J Endovasc Ther 2002;9:38-47.

15. Carr SC, Pearce WH, Vogelzang RL, et al. Current management of visceral artery aneurysms. Surgery 1996;120:627-33; discussion 633-4.

This pdf has been created automatically from the final edited text and images.

Copyright 2011 BMJ Publishing Group. All rights reserved. For permission to reuse any of this content visit http://group.bmj.com/group/rights-licensing/permissions.

BMJ Case Report Fellows may re-use this article for personal use and teaching without any further permission.

Please cite this article as follows (you will need to access the article online to obtain the date of publication).

Janmohamed A, Noronha L, Saini A, Elton C. An unusual cause of lower gastrointestinal haemorrhage. BMJ Case Reports 2011;

10.1136/bcr.11.2011.5102, Published XXX

Become a Fellow of BMJ Case Reports today and you can:

- Submit as many cases as you like

- Enjoy fast sympathetic peer review and rapid publication of accepted articles

- Access all the published articles

- Re-use any of the published material for personal use and teaching without further permission

For information on Institutional Fellowships contact consortiasales@bmjgroup.com

Visit casereports.bmj.com for more articles like this and to become a Fellow 